\title{
The Pathway of Carbon in Nature
}

Draft 3.0 incorporating Science edits, 3 May 2006

A "Perspective” for Science, introducing the paper

Biomarker Evidence for a Major Preservation Pathway of Sedimentary Organic Carbon

by Y. Hebting, P. Schaeffer, A. Behrens, P. Adam, G. Schmitt,

P. Schneckenburger, S. Bernasconi, and P. Albrecht

John M. Hayes, Woods Hole Oceanographic Institution

Late in his exceptional career, well after he'd received the Nobel Prize for elucidating the pathway of carbon in photosynthesis, Melvin Calvin turned his attention to organic geochemistry. The progression was logical: from the pathway of carbon in a cell to the pathway of carbon in nature. In the former, there is an array of precise, enzymatic catalysts. The latter is actually a web of reactions that leads from primary biological products to the organic debris accumulating in earth's crust. What mechanisms control the flows of carbon within it? It's worth knowing because, among other things, those mechanisms modulate Earth's levels of $\mathrm{CO}_{2}$ and $\mathrm{O}_{2}$. On page $x x x$ of this issue, Hebting et al.(1) provide striking new information about one of the web's most general features.

In his book on Chemical Evolution (2), Calvin discusses "molecular paleontology" and makes a key point: hydrocarbons are particularly long-lived. Petroleum is a key example. In contrast, proteins, carbohydrates, and nucleic acids - the abundant and information-rich components of biomass-are rarely preserved for more than a few million years (3). Clues about ancient biochemistry must therefore be extracted from sedimentary hydrocarbons derived mainly from lipids and other aliphatic products.

The rocks contain cholestane rather than cholesterol, carotane rather than carotene. The structural relationships are unmistakable but the molecules are very different. Somehow, carbon skeletons are preserved, double bonds and functional groups are lost, and a saturated hydrocarbon survives to carry the root of its precursor's name with an “-ane” suffix.

How does all of this happen? The hydrocarbons — called "biomarkers" if their structures are distinct enough — are produced by reaction pathways within sediments. For years, organic geochemists have been disentangling those pathways just as Calvin, Benson, and their coworkers determined the route from $\mathrm{CO}_{2}$ to carbohydrates.

The time scales differ markedly, however. In photosynthesis, the problem was to stop reactions quickly so that the earliest products could be observed. In sediments, even the faster reactions require decades to produce readily analyzable quantities. Moreover, if a system is manipulated — to speed it up or to add a tracer - the pathways are likely to change. The most useful results have been based on analyses of natural materials at identifiable points in the pathway.

Sterols, which are abundant in oceanic algae and for which structurally related steranes can be found in marine sediments and petroleum, have been favored as tracers within the web of reactions (4). Even within particles that have not yet sunk to the seafloor, we find hydrogenated products, stanols rather than the original algal products. Evidence for microbial catalysis of this process is strong (5). Double bonds within the ring system are the first to go (for example that at position 5 in cholesterol) and the process is stereoselective. The hydrogenated products are more abundant in environments that are deficient in 
oxygen (such as interiors of particles or poorly ventilated waters). Apparently, microorganisms are extending their oxidative metabolism by using unsaturated lipids as electron acceptors.

Microorganisms also dehydrate sterols to produce conjugated steradienes (6). In the dehydration of carotenoids, formation of an acetylenic intermediate that would not be favored in abiotic processes also suggests microbial catalysis (7). As such results have accumulated, a new conventional wisdom has emerged: if the temperature is not too high and a reaction could be microbially catalyzed, it probably is.

Or is it just hard to prove when a low-temperature, organic-chemical alteration is abiotic? It's not as if sedimentary environments are chemically benign. Concentrations of $\mathrm{H}_{2} \mathrm{~S}$, a potential reductant, can be appreciable. The figure shows that iron traps quite a bit of the sulfide produced by sulfate-reducing bacteria. Supplies of $\mathrm{H}_{2} \mathrm{~S}$ are, however, so large that excess sulfide is available to react with any organic molecules that might be present. Carotenoid pigments, which are rich in double bonds, would be particularly reactive. And here is the difficulty. The range of reduction products found in sediments is huge. One can look at it and say "It's a mess, it must be abiotic," but that does not eliminate the possibility of varying degrees of microbial alteration.

Hebting et al. work closely with natural-products organic chemists. The resulting expertise has helped them to separate the components of the "mess." Employing a formidable array of spectroscopic techniques, they have elucidated molecular structures. Wherever it has been possible to pin down the stereochemistry at chiral centers, the results show that the hydrogenations were not stereoselective and, therefore, not microbially catalyzed.

Must the conventional wisdom be revised, at least for hydrogenations? Probably. The proven microbial hydrogenations are quite specific whereas the pathway now demonstrated is general. And practically every aerobic-anaerobic boundary includes a sulfide-rich zone. In fact, another group (8) showed earlier that formation of sulfide bridges - a sort of natural vulcanization-is an important process by which reactive organic molecules are immobilized by attachment to insoluble macromolecules in sediments.

A second phase of the present work is therefore important. In laboratory experiments (1), Hebting et al. have demonstrated hydrogenation of double bonds in carotenoids and steroidal ketones incubated at 50 to $90^{\circ} \mathrm{C}$ in saturated solutions of $\mathrm{H}_{2} \mathrm{~S}$. Yields are low but, as the authors say, the results, and observation of the proposed intermediates in some natural sediments, "support” a hypothetical, two-step process: (i) addition of $\mathrm{H}_{2} \mathrm{~S}$ to a polyene to yield an allylic thiol, and (ii) reduction of the thiol. If a double bond is conjugated with a carbonyl group rather than another olefinic bond, initial sulfurization is apparently not required and a different mechanism applies.

Without doubt, this report erects a new, and highly significant, milepost on the pathway of carbon in nature.

\section{References}

1. Y. Hebting et al., Science 312, xxx (2006); published online...

2. M. Calvin, Chemical Evolution (Oxford University Press, New York, 1969).

3. G. Eglinton, G. A. Logan, Phil. Trans. Roy. Soc. London B 333, 315 (1991).

4. A. S. Mackenzie, S. C. Brassell, G. Eglinton, J. R. Maxwell, Science 217, 491 (1982).

5. J. A. Beier, S. G. Wakeham, C. H. Piskaln, S. Honjo, Nature 351, 642 (1991). 
6. R. B. Gagosian, J. W. Farrington, Geochim. Cosmochim. Acta 42, 1091 (1978).

7. D. J. Repeta, N. Frew, Org. Geochem. 12, 469 (1988).

8. M. E. L. Kohnen, J. S. Sinninghe Damsté, H. L. ten Haven, J. W. de Leeuw, Nature 341, 640 (1989). 


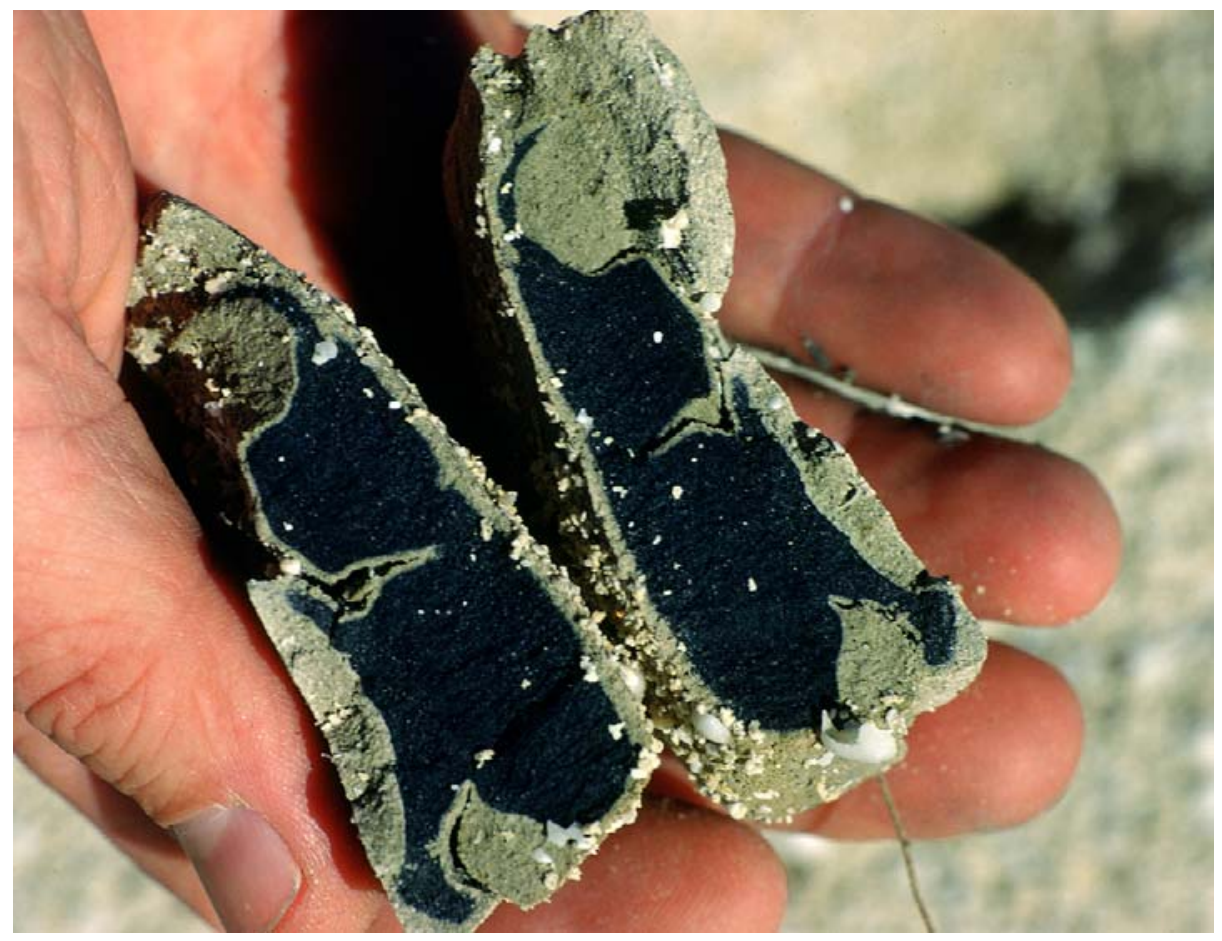

Natural sulfide. Cracked open, a clump of gelatinous mud from the seaside is seen to be rich in black iron sulfide. Any hydrogen sulfide that does not react with iron is available to react with organic matter. The sulfide is produced by bacteria that oxidize organic matter at the expense of sulfate, which is abundant in seawater. The process occurs only after molecular-oxygen supplies have been exhausted. The light-colored margin of the clump marks the depth to which molecular oxygen can diffuse in the mud. 